\title{
Population genetic structure of the parasitic copepod Lepeophtheirus salmonis throughout the Atlantic
}

\author{
Kevin A. Glover ${ }^{1, *}$, Åsta B. Stølen ${ }^{2}$, Amber Messmer ${ }^{3}$, Ben F. Koop ${ }^{3}$, Ole Torrissen ${ }^{1}$, \\ Frank Nilsen ${ }^{1,2}$
}

\author{
${ }^{1}$ Institute of Marine Research, PO Box 1870 Nordnes, 5817 Bergen, Norway \\ ${ }^{2}$ Department of Biology, University of Bergen, PO Box 7800, 5020 Bergen, Norway \\ ${ }^{3}$ Department of Biology, University of Victoria, Victoria, British Columbia V8W 3N5, Canada
}

\begin{abstract}
The parasitic copepod Lepeophtheirus salmonis is responsible for huge economic losses in the salmonid aquaculture industry, and has been linked with declines of wild salmonid populations. In order to elucidate population genetic structure throughout the Atlantic Ocean, 2495 lice representing 27 samples collected from 22 locations were analysed for 14 microsatellite loci. Significant overall genetic variation was observed (14 loci: global $F_{\mathrm{ST}}=0.0057, \mathrm{p}<0.0001$ ), although this decreased slightly when an outlier locus (LsalSTA3), detected as a candidate for positive selection, was removed (13 neutral loci: global $\left.F_{\mathrm{ST}}=0.0022, \mathrm{p}<0.0001\right)$. A relationship between physical and genetic distance was observed $\left(\mathrm{R}^{2}=0.179, \mathrm{p}=0.0013\right)$, but only when data from LsalSTA3 was included. No overall genetic variation was observed among the 19 samples collected in Norway (Norwegian global $F_{\mathrm{ST}}<0.0001, \mathrm{p}=0.6$ ). None of the within-country (Canada, Ireland, Shetland and Faroe Islands) pairwise $F_{\mathrm{ST}}$ values were statistically significant when analysing the 13 neutral loci and following Bonferroni correction. Samples taken at 5 Norwegian farms did not exhibit significant genetic differences before and after medicated treatment. We conclude that $L$. salmonis displays weak but nevertheless statistically significant population genetic variation throughout the Atlantic. Analysis of temporal samples, potentially combined with larger numbers of markers giving greater genome coverage, will be required to fully elucidate the biological significance of the observed variation.
\end{abstract}

KEY WORDS: Copepod $\cdot$ Salmon louse $\cdot$ Population $\cdot$ Dispersal $\cdot$ Resistance $\cdot$ Microsatellite

\section{INTRODUCTION}

The sea louse Lepeophtheirus salmonis is an ectoparasitic copepod infecting salmonid fishes in the marine environment. Occurring in both the Pacific and Atlantic oceans, this common parasite is responsible for significant economic losses in Atlantic salmon Salmo salar farming (Johnson et al. 2004, Costello 2009), and has been associated with declines of wild salmonid populations (Krkošek et al. 2007). It is highly likely that the increase of salmonid cage-farming in coastal areas has led to an increase in the numbers of $L$. salmonis to which wild salmonids are exposed (Heuch \& Mo 2001). This is supported by the fact that higher infection levels are often observed on wild salmonids in regions of intensive cage-aquaculture (Tully et al. 1999, Bjørn \& Finstad 2002, Morton et al. 2004).

A range of strategies are implemented to control lice infestations on farmed salmonids (Pike \& Wadsworth 2000); however, the industry is reliant upon medicated treatments administered as baths or feed (Burridge et al. 2010). Reduced sensitivity and/or resistance of Lepeophtheirus salmonis to medicated treatments have been documented in Atlantic populations (Jones et al. 
1992, Treasurer et al. 2000, Tully \& McFadden 2000, Sevatdal \& Horsberg 2003, Fallang et al. 2004), and the efficacy of treatments has decreased over time (Lees et al. 2008). Therefore, a vital issue from both an evolutionary and management perspective is the dispersal of lice. How far and how fast will lice that display resistance to specific chemicals transfer between regions, countries and continents?

Lepeophtheirus salmonis displays a life cycle with 2 distinct opportunities for dispersal. First, planktonic larval stages, lasting approximately $13 \mathrm{~d}$ at $10^{\circ} \mathrm{C}(\mathrm{John}$ son \& Albright 1991) provide the opportunity to be transported with ocean currents, typically ranging from 10 to $50 \mathrm{~km}$ (Costello 2006). Once settled on an Atlantic salmon, or sea trout Salmo trutta, which represent the primary hosts for L. salmonis in the Atlantic Ocean, they may be transported further while they mature and reproduce, spreading more planktonic larvae into the environment. Although sea trout tend to remain in coastal areas, usually migrating $<50 \mathrm{~km}$ from the source river (Jonsson 1985, Berg \& Berg 1987), Atlantic salmon undertake long-distance migrations, and individuals originating from populations in both the west and east Atlantic may mix on the ocean feeding grounds (Hansen \& Jacobsen 2003). The presence of all lice stages on salmon in these areas indicates that cross-infection in open water may occur (Holst et al. 1993, Jacobsen \& Gaard 1997).

With this potential for long-distance dispersal, it could be reasoned that Lepeophtheirus salmonis is likely to be represented by a single population throughout the Atlantic. However, data from the literature are divided on this issue. Analysis of 4 mitochondrial DNA (mtDNA) genes (Tjensvoll et al. 2006) and 6 microsatellite DNA markers (Todd et al. 2004) revealed weak or no statistically significant genetic differentiation throughout the Atlantic, respectively. Conversely, studies conducted on lice from the Pacific using the cytochrome $c$ oxidase subunit I (COI) mtDNA gene (Boulding et al. 2009), in Scotland with random amplification of polymorphic DNA (RAPD) markers (Dixon et al. 2004) and in Ireland with 4 microsatellite DNA markers (Nolan \& Powell 2009) have identified highly significant spatial and temporal genetic structure. However, previous L. salmonis population genetic studies conducted in the Atlantic are characterised by small-to-modest sample sizes (Nolan et al. 2000, Tjensvoll et al. 2006, Nolan \& Powell 2009), technical challenges (Todd et al. 1997, Dixon et al. 2004) and low numbers of polymorphic loci (Nolan et al. 2000, Todd et al. 2004, Nolan \& Powell 2009).

In light of the fact that Lepeophtheirus salmonis is an ecologically and economically important parasite, and that evolving resistance to medicated treatments is making management of this parasite both increasingly challenging and important, the present study was designed to further elucidate the population genetic structure of $L$. salmonis in the Atlantic. In order to advance on previous studies, the approach included (1) collection and analysis of large numbers of samples throughout the Atlantic (27 samples from 22 locations), (2) analysis of large numbers of lice per sample (79 to 94), (3) analysis of 16 microsatellites as opposed to 6 or less implemented in previous studies based upon samples collected from the Atlantic, and (4) analysis of samples taken on farms before and after medicated treatment in order to test whether delousing can influence estimates of temporal and spatial genetic differentiation.

\section{MATERIALS AND METHODS}

Samples. A total of 2514 Lepeophtheirus salmonis, representing 27 samples, were collected on 22 fish farms located throughout the Northern Atlantic in the summer and autumn of 2009 (Fig. 1). Nineteen individuals were later excluded due to DNA extraction failure, leaving the data set to consist of 2495 lice. Some of the samples were collected on fish as they were slaughtered, while other samples were taken in association with routine lice-counting on farms. As large genetic differences between L. salmonis in the Pacific and Atlantic have previously been well documented (Todd et al. 2004, Tjensvoll et al. 2006, Yazawa et al. 2008), no outlier sample from the Pacific was included. For Canada, Ireland, Shetland and the Faroe islands, 2 samples country ${ }^{-1}$ were collected. The remaining 19 samples were taken in Norway. The prefixes C (Canada), F (Faroe Islands), S (Shetland), I (Ireland) and $\mathrm{N}$ (Norway) were used before individual sample numbers to aid presentation.

Ten of the Norwegian samples originated from 5 farms located within the county of Hordaland (southwest). Sampling on these 5 farms was conducted prior to (T1) and post delousing (T2) with medicated treatments in order to investigate whether temporal and spatial genetic variation within a small geographic region may be affected by the process of delousing, as suggested previously (Nolan \& Powell 2009). Details regarding the delousing history on these 5 farms were collected.

Genotyping. DNA was extracted in a 96-well format using the Qiagen DNeasy kit. Each 96-well tray contained a minimum of 2 blank controls and Lepeophtheirus salmonis representing 1 sample. A total of 16 microsatellite loci were amplified in 3 multiplex reactions: Multiplex 1 included LsalSTA1, LsalSTA2, LsalSTA4, LsalSTA5 (Todd et al. 2004) and LsNUIG14 adapted by Todd et al. (2004); Multiplex 2 included Lsal103EUVC, Lsal109EUVC, Lsal110EUVC, Lsal111- 


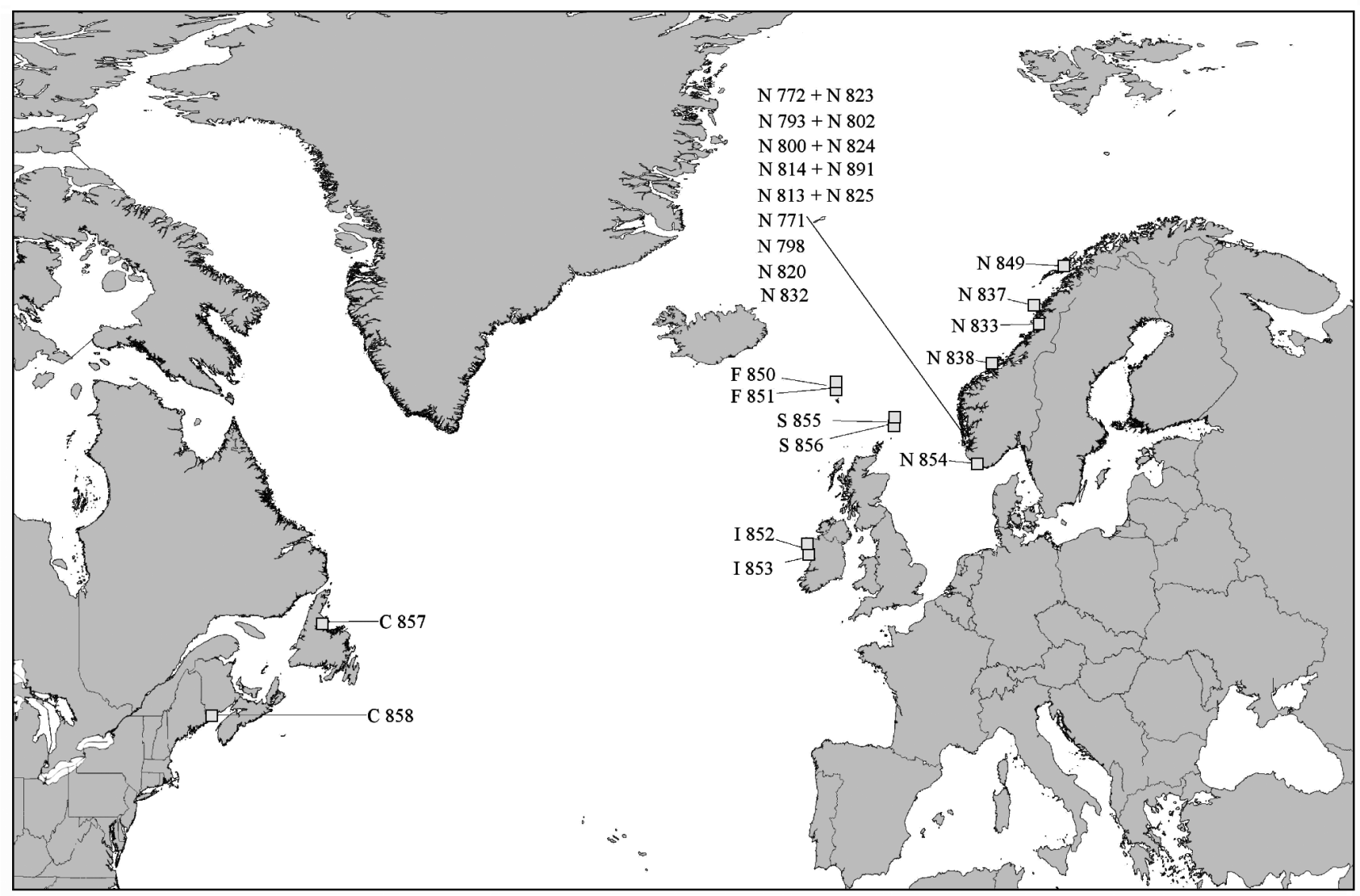

Fig. 1. Lepeophtheirus salmonis. Sample locations throughout the Atlantic. The letter in front of a sample number indicates the source: $\mathrm{C}=$ Canada, $\mathrm{F}=$ Faroe Islands, $\mathrm{I}=$ Ireland, $\mathrm{N}=$ Norway, $\mathrm{S}=$ Shetland

EUVC (Messmer et al. in press) and LsNUIG09 (Nolan et al. 2000); and Multiplex 3 included Lsal104EUVC, Lsal105EUVC, Lsal106EUVC, Lsal108EUVC (Messmer et al. in press), LsalSTA3 (Todd et al. 2004) and LsNUIG35B (Nolan \& Powell 2009). Amplification conditions are available upon request from the authors. PCR fragments were separated on an ABI 3730XL sequencer and sized relative to the Applied Biosystem GeneScan $^{\mathrm{TM}}$ 500LIZ ${ }^{\mathrm{TM}}$ size standard. Alleles were scored using automatic binning implemented in the Genmapper software (v. 4.0). Allele scoring was controlled independently by 2 persons.

In order to control genotyping quality, 80 lice were selected randomly from the original DNA isolation plates and re-analysed blind for all markers. Routine checking of genotyping quality has been recommended by several authors (Hoffman \& Amos 2005, Pompanon et al. 2005). Genotyping quality was further examined with the program MICRO-CHECKER (Van Oosterhout et al. 2004), which highlights potential problems with null alleles, large allele dropout, and stuttering.

Statistical analyses. Some statistical measurements (i.e. average measures such as locus heterozygosity and global $F_{\mathrm{ST}}$ values) will be influenced by the num- ber and relatedness of samples included in the computations. In the present study, intense sampling in Southwest Norway was conducted in order to investigate whether genetic differentiation can exist among samples collected in a small geographic region. Clearly, inclusion of the 19 samples from Norway would have an overly strong influence on the Atlanticwide pattern of genetic differentiation. Consequently, in order to address specific questions, and improve presentation, the samples were arranged in 3 partially overlapping data sets for statistical analysis. These are hereafter referred to as the 'full Atlantic' data set (all 27 samples throughout the Atlantic), the 'reduced Atlantic' data set (11 samples representing the northern Atlantic, 2 per country, 3 from Norway), and the 'Norway' data set (19 samples taken along the Norwegian coastline).

The program MSA (Dieringer \& Schlotterer 2003) was used to compute summary statistics and fixation index $\left(F_{\mathrm{ST}}\right)$ values (a measure of genetic distance among populations). The program Genepop (Raymond \& Rousset 1995) was used to test for deviation from Hardy-Weinberg equilibrium (HWE), and to test for evidence of linkage disequilibrium (LD) between pairs 
of loci within each sample. HWE is the state at which genotype frequencies in a population remain stable, while LD is the non-random association of alleles at 2 or more loci. Both these parameters were examined statistically by Fisher's exact test (dememorisation 10 000; 100 batches; 5000 iterations). Significance level was presented at $\alpha=0.05$ and $\alpha=0.001$, in addition to applying Bonferroni correction for multiple tests. Genepop v. 3.3 was used to estimate observed $\left(H_{\mathrm{o}}\right)$ and expected $\left(H_{\mathrm{e}}\right)$ heterozygosities (i.e. the fraction of individuals that are heterozygous in a population) and the inbreeding coefficient $F_{\text {is }}$. The program LOSITAN (Antao et al. 2008) was used to test the loci for neutrality. This program utilises an $F_{\mathrm{ST}}$ outlier detection method in order to identify loci that are potential candidates for balancing and positive selection.

The potential relationship between geographic $(\mathrm{km})$ and genetic $\left(F_{\mathrm{ST}}\right)$ distance was computed by generating a matrix of physical distances from a map, and regressing these against a matrix of pairwise $F_{\mathrm{ST}}$ values. This was conducted for the reduced Atlantic data set using different combinations of loci.

Bayesian clustering analysis implemented in STRUCTURE 2.2 (Pritchard et al. 2000, Falush et al. 2003) was used for detecting the number of populations and assigning individuals to groups without using prior information about their origin. Runs were conducted at $k=1$ to 5 , each with 5 iterations. Correlated allele frequencies and an admixture model were assumed. Each run consisted of a burn-in of 100000 Markov chain Monte Carlo (MCMC) steps, followed by 200000 steps. Pilot runs varying $k$, MCMC steps and using the population of origin as a prior were tested without giving significantly different results.

\section{RESULTS}

\section{Genotyping quality and marker neutrality}

The 3 multiplexes produced distinct fragments for all 16 markers; however, the pattern of alleles at locus LsNUIG35B was not clear, and consequently, this locus was excluded from all analyses. Of the 80 samples reanalysed for the 15 scored markers, only 2 genotyping inconsistencies were observed, giving an overall genotyping error rate $<0.15 \%$. Genotyping errors included a single homozygote/heterozygote inconsistency for $L$ sal105EUVC, and a $1 \mathrm{bp}$ discrepancy for a single allele at LsalSTA3. Both genotypes were excluded from the data set.

MICRO-CHECKER (Van Oosterhout et al. 2004) reported homozygote excess for all 27 samples at the locus Lsal104EUVC, suggesting the presence of null alleles. This locus was subsequently removed. No other genotyping abnormalities were observed for any of the other loci, and the remaining data set was regarded as robust. For the 2495 lice scored at the 14 loci (34 930 potential genotypes), >98\% genotyping coverage was attained.

Prior to further statistical analyses, neutrality of the 14 loci was examined by using LOSITAN (Antao et al. 2008). The locus LsalSTA3 was identified as an outlier and a candidate for positive selection (Fig. 2). Conse-

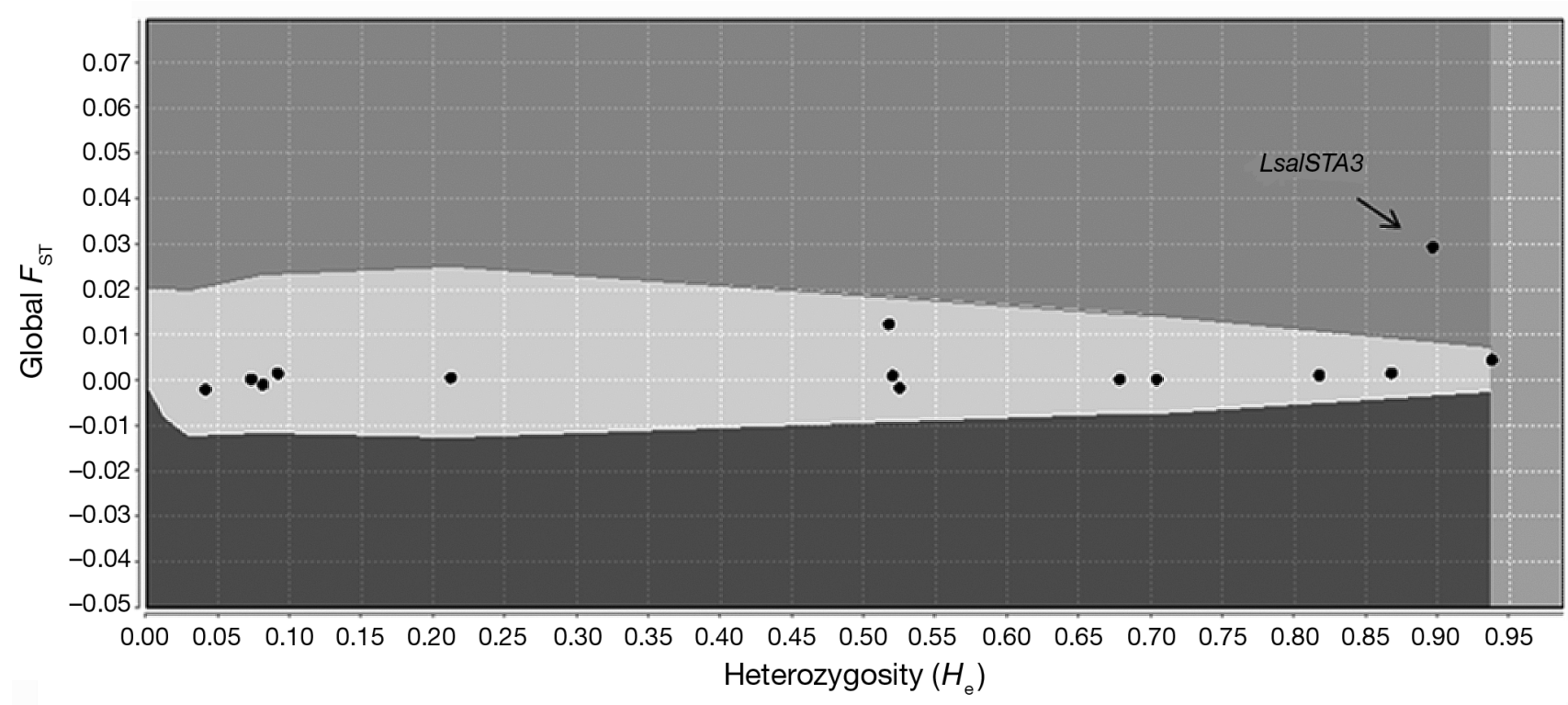

Fig. 2. Lepeophtheirus salmonis. Identification of outlier loci using the program LOSITAN (Antao et al. 2008). Upper grey area represents candidates for positive selection, middle light area candidate for neutral loci, and lower dark grey area candidates for balancing selection. Markers are indicated by $\bullet$. Marker LsalSTA3 represents the single outlier from the 14 loci analysed. $F_{\mathrm{ST}}=$ fixation index, $H_{\mathrm{e}}=$ expected heterozygosity 
quently, tests of genetic differentiation among samples were conducted using the 13 neutral loci, in addition to the full set of 14 loci.

\section{Genetic variation within samples}

Summary statistics for the full Atlantic and Norway data sets (Tables S1 \& S3 in Supplement 1 at www. int-res.com/articles/suppl/m427p161_supp1.pdf), in addition to the reduced Atlantic data set (Table 1; Table S2 in Supplement 1), are presented. Within the full Atlantic data set, a total of 257 alleles were observed for the 14 loci, giving a mean of 18.4 alleles locus $^{-1}$. Within populations, the total number of alleles displayed very little variation, ranging from 128 in Sample S856, to 149 in Sample N849. $H_{\mathrm{o}}$ averaged over all loci ranged from 0.436 in Sample I853 to 0.479 in Sample F851, and $F_{\text {is }}$ values pooled over loci were all slightly positive (0.015 in Sample C858 to 0.076 in Sample N838). Polymorphism varied among markers, ranging from a total of 6 alleles observed at Lsal110EUVC to 37 alleles observed at LsalSTA2, and $H_{\mathrm{e}}$ (over all 27 samples) ranged from a low of 0.074 in Lsal103EUVC to 0.936 in LsalSTA5.

From a total of 378 tests computed in the full Atlantic data set, 31 and 4 significant deviations from HWE were observed at $\alpha=0.05$ and $\alpha=0.001$ respectively (Table 1; Table S1 in Supplement 1). These deviations were distributed among populations and loci. Focusing first on loci, LsalSTA5 and LsalSTA3 were each implicated in 6 deviations at $\alpha=0.05$, while LsalSTA4 represented the only locus not implicated in any significant deviation. Following Bonferroni correction (14 loci: adjusted critical $\mathrm{p}=0.0035$ ), only 5 deviations remained significant (LsNUIG09 had 3, Lsal110EUVC had 1 and LsalSTA3 had 1). Focusing on samples, 8 out of 27 did not display any deviations from $\mathrm{HWE}_{\text {; }}$ the majority displayed deviations in 1 or 2 of the markers, while 2 samples displayed deviations in 3 markers (Samples N825 and N832). Following Bonferroni correction (27 samples: adjusted critical $p=0.0019$ ), only 3 deviations remained significant (1 each in Samples N772, N813 and N814).

From a total of 2821 within-population locus-bylocus tests of LD, 135 pairs displayed significance at $\alpha=0.05$ (data not shown). At $\alpha=0.001$, only 8 of these tests remained significant, and with the exception of the combination LsalSTA5 and LsalSTA2 occurring twice, LD was spread among pairs of loci. Bonferroni correction was not applied to these results; however, the lack of any clear LD between pairs of loci enabled them to be treated as independent for all statistical analyses.

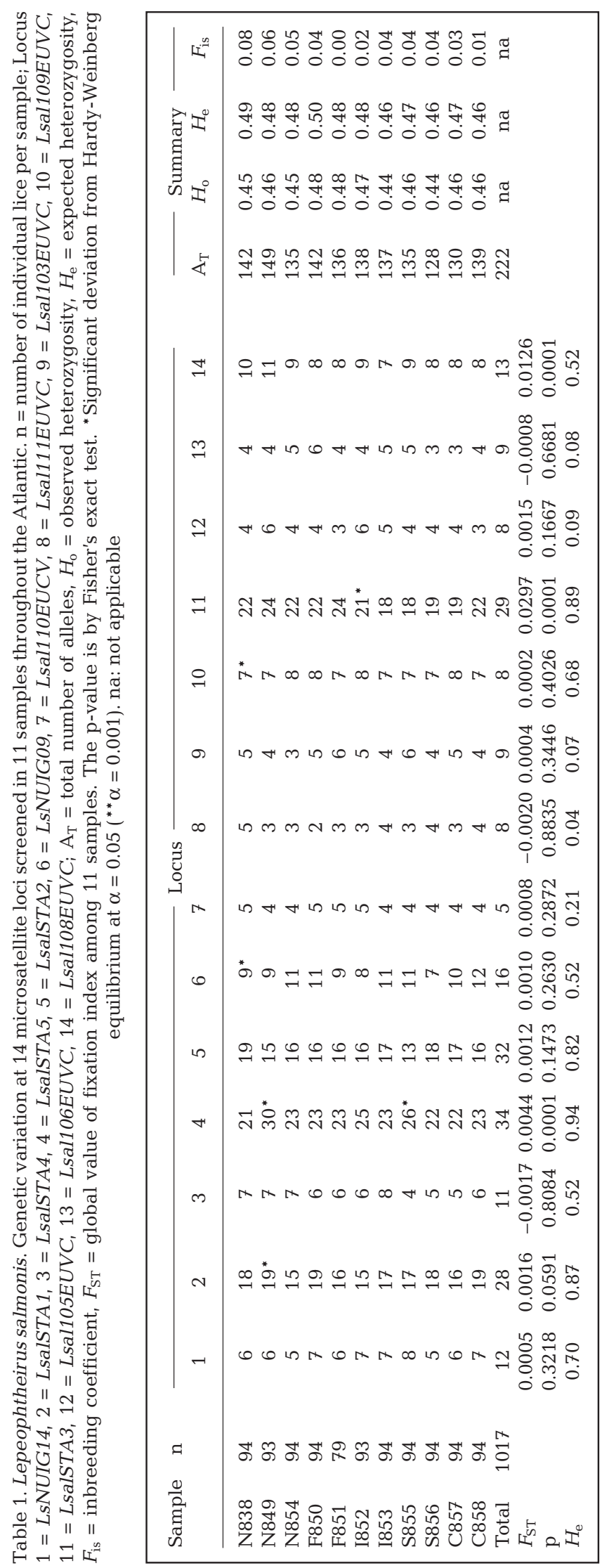




\section{Genetic variation throughout Norway}

Among the 19 samples collected in Norway, no overall genetic variation was observed (13 loci: global $F_{\mathrm{ST}}<$ 0.0001, $\mathrm{p}=0.6$; 14 loci: global $\left.F_{\mathrm{ST}}<0.0001, \mathrm{p}=0.5\right)$. This overall result was corroborated by the fact that only 1 of the 14 loci gave global $F_{\mathrm{ST}}$ values significantly different from zero (LsalSTA4: $F_{\mathrm{ST}}=0.0037, \mathrm{p}=0.017$ ), and this was not significant following Bonferroni correction (adjusted critical $\mathrm{p}=0.035$ ) (Table S3 in Supplement 1).

When considering the 13 neutral loci together, 8 out of 171 pairwise comparisons among the 19 Norwegian samples were significant at $\alpha=0.05$; however, only 1 remained significant at $\alpha=0.001$ (Sample N802 vs. Sample N825: $F_{\mathrm{ST}}=0.007, \mathrm{p}=0.0001$; Tables S6 \& S7 in Supplement 2 at www.int-res.com/articles/suppl/ m427p161_supp2.xls). This difference remained significant following Bonferroni correction (adjusted critical $\mathrm{p}=0.0003$ ). The 2 samples displaying weak albeit significant differentiation to each other were taken from the same region (Fig. 1), and both represent samples taken immediately after delousing with medicated treatment (Table 2). Although $F_{\mathrm{ST}}$ and associated p-values changed, pairwise comparisons using data from all 14 as opposed to the 13 loci displayed a very similar trend among the Norwegian samples (Tables S4 \& S5 in Supplement 2). For example, the 8 pairwise comparisons significant at $\alpha=0.05$ using 13 loci were the same pairs when computed with 14 loci. Furthermore, it was the same pair of samples (N802 vs. N825) that remained significantly different to each other when applying Bonferroni correction, and the $F_{\mathrm{ST}}$ value was very similar (14 loci: $F_{\mathrm{ST}}=$ 0.0066; 13 loci: $\left.F_{\mathrm{ST}}=0.007\right)$.

Of the 5 farms where lice were sampled prior to and post delousing (Table 2), 3 farms (1, 3 and 5) exhibited 'successful' delousing treatments (defined as the situation whereby numbers of lice dropped to $<0.5 \mathrm{fish}^{-1}$ on average within $1 \mathrm{wk}$ following treatment) between T1 and T2. However, all 3 of these farms displayed infection levels similar to, or higher, in T2 compared to T1. This increased infection represents a combination of lice not removed by the initial delousing treatment, settlement of new lice on the fish from nearby farms, and finally, settlement of lice from wild fish. Nevertheless, none of the temporal samples collected on the farms displayed significant genetic differences between T1 and T2, with either 13 (Table 2) or 14 loci (Tables S4 \& S5 in Supplement 2).

Table 2. Lepeophtheirus salmonis. Comparisons of lice sampled prior to (T1) and post delousing treatment (T2) on 5 Norwegian farms. Based upon data from 13 neutral microsatellite loci. $F_{\mathrm{ST}}=$ fixation index; Week = week of the year; Temp. = seawater temperature; $\mathrm{S}=$ stationary (i.e. chalimus) and $\mathrm{M}=$ motile (i.e. pre and adults) stages observed on fish in cage at time of sampling; 'Successfully' = situation whereby the numbers of lice dropped to $<0.5 \mathrm{fish}^{-1}$ on average within 1 wk following treatment and does not indicate that all lice on the farm were killed by treatment

\begin{tabular}{|c|c|c|c|c|c|c|c|c|c|c|c|c|c|}
\hline \multirow[t]{3}{*}{ Farm } & \multirow{3}{*}{ Sample } & \multirow{3}{*}{$\overline{\text { Week }}$} & \multirow{2}{*}{\multicolumn{3}{|c|}{$\begin{array}{l}\text { T1 } \\
\text { Temp. No. of lice }\end{array}$}} & \multirow{3}{*}{ Sample } & \multirow{3}{*}{ Week } & \multirow{3}{*}{$\begin{array}{l}\text { T2 } \\
\text { Temp. } \\
\left({ }^{\circ} \mathrm{C}\right)\end{array}$} & \multirow{2}{*}{\multicolumn{2}{|c|}{ No. of lice }} & \multirow{3}{*}{$F_{\mathrm{ST}}$} & \multirow[t]{3}{*}{$\mathrm{p}$} & \multirow[t]{3}{*}{ Treatment history in 2009} \\
\hline & & & & & & & & & & & & & \\
\hline & & & $\left({ }^{\circ} \mathrm{C}\right)$ & $\mathrm{S}$ & $\mathrm{M}$ & & & & $\mathrm{S}$ & $\mathrm{M}$ & & & \\
\hline 1 & N772 & 36 & 16 & 0 & 4 & N823 & 43 & 10 & 0 & 5 & 0.0004 & 0.35 & $\begin{array}{l}\text { Treated 'successfully' } \\
\text { (alphamax) in Weeks } 3 \text { and 20, } \\
\text { unsuccessfully in Week 34, } \\
\text { 'successfully' (betamax) in } \\
\text { Week } 37, \text { and unsuccessfully } \\
\text { (alphamax) in Week } 42 . \text { New } \\
\text { infection post week } 37\end{array}$ \\
\hline 2 & N793 & 37 & 16 & 0 & 5 & N802 & 40 & 12 & 0 & 8 & -0.0007 & 0.67 & $\begin{array}{l}\text { Treated 'successfully' in } \\
\text { Weeks } 3 \text { (alphamax) and } 30 \\
\text { (betamax), and unsuccessfully } \\
\text { (alphamax) in Week } 38\end{array}$ \\
\hline 3 & N800 & 39 & 15 & 0 & 9 & N824 & 45 & 9 & 2 & 15 & -0.0004 & 0.56 & $\begin{array}{l}\text { Treated 'successfully' } \\
\text { (alphamax) in Weeks } 16 \text { and } \\
40 . \text { New heavy settlement post } \\
\text { Week } 40\end{array}$ \\
\hline 4 & N813 & 43 & 10 & 2 & 3 & N825 & 47 & 9 & 1 & 3 & 0.0016 & 0.14 & $\begin{array}{l}\text { Treated unsuccessfully } \\
\text { (Diflubenzuron EWOS) in } \\
\text { Weeks } 44 \text { and } 45\end{array}$ \\
\hline 5 & N814 & 42 & 11 & 0 & 3 & N891 & 52 & 7 & 2 & 2 & 0.0008 & 0.25 & $\begin{array}{l}\text { Treated 'successfully' } \\
\text { (alphamax) in Week } 46 . \text { New } \\
\text { infection post Week } 46\end{array}$ \\
\hline
\end{tabular}




\section{Genetic variation throughout the Atlantic}

When calculated for the reduced Atlantic data set, 3 of the 14 loci gave significant global $F_{\mathrm{ST}}$ values, all of which remained significant following Bonferroni correction (14 loci: adjusted critical $\mathrm{p}=0.0036$ ) (Table 1 ). These were LsalSTA5, Lsal108EUVC and LsalSTA3 (the latter of which was already demonstrated by be a candidate for positive selection) (Fig. 2). When calculated for the full Atlantic data set, the same 3 loci were also identified as the only markers displaying significant global $F_{\mathrm{ST}}$ values following Bonferroni correction (Table S1 in Supplement 1).

When pooling loci, significant overall genetic differentiation was observed among samples collected throughout the Atlantic. This was observed for the reduced Atlantic data set when analysed by 13 loci (global $F_{\mathrm{ST}}=0.0022, \mathrm{p}<0.0001$ ) and 14 loci (global $\left.F_{\mathrm{ST}}=0.0057, \mathrm{p}<0.0001\right)$, in addition to the full Atlantic data set when analysing 13 (global $F_{\mathrm{ST}}=0.0009$, p < 0.0001 ) and 14 loci (global $F_{\mathrm{ST}}=0.0028, \mathrm{p}<0.0001$ ). Clearly, inclusion of the multiple samples from Norway, which were already demonstrated to be genetically similar to each other, was responsible for decreasing the global (i.e. average) $F_{\mathrm{ST}}$ estimate in the full Atlantic compared to the reduced Atlantic data set. Inclusion of the outlier locus LsalSTA3 increased all global $F_{\text {ST }}$ values.

In the reduced Atlantic data set, pairwise $F_{\mathrm{ST}}$ values pooled over the 13 loci varied from zero, to a maximum of 0.0078 ( $p=0.0001$ ) (Table 3). This was observed between samples I853 and F850, and remained as the only statistically significant pairwise comparison in the reduced Atlantic data set when analysing 13 markers, and, following Bonferroni correction (adjusted critical $\mathrm{p}=0.0009$ ). When considering LsalSTA3 only, pairwise $F_{\mathrm{ST}}$ values in the reduced Atlantic set were as high as
0.11 , and, many of the pairwise comparisons were statistically significant, even after Bonferroni correction (Table 3).

In the full Atlantic data set, the largest pairwise $F_{\mathrm{ST}}$ for the 13 neutral loci was 0.0083 ( $\mathrm{p}=0.0001)$, which was observed between Samples I853 and N825. This also remained significant following Bonferroni correction (adjusted critical $\mathrm{p}=0.00014$ ) (Tables S6 \& S7 in Supplement 2). In total, 4 of 351 pairwise comparisons remained significant in the full Atlantic data set when using the 13 loci and following Bonferroni correction.

When considering data from the 14 loci together in the full Atlantic data set, the highest pairwise $F_{\mathrm{ST}}$ value was 0.0168 ( $\mathrm{p}<0.0001$ ) (Sample S856 vs. Sample C858) (Tables S4 \& S5 in Supplement 2), and 33 pairwise $F_{\mathrm{ST}}$ values exceeded 0.01, all of which remained significant following Bonferroni correction (adjusted critical $\mathrm{p}=$ $0.00014)$. Most of these deviations were caused by Samples I853, S856 and C858 being different from the majority of the other samples, and none of the $F_{\mathrm{ST}}$ values $>0.01$ were reported between pairs of samples taken from the same country (including Norway).

Private alleles were observed in all countries (Table 4). While the number of private alleles was clearly dependent on the numbers of samples included in the analysis, a total of 61 and 43 private alleles, out of an allelic total of 257, were observed in the full and reduced Atlantic data sets respectively. The majority of private alleles were observed as a single copy, but this was also dependent upon the numbers of samples included in the analysis.

In order to investigate whether there was any cryptic genetic structure, Bayesian clustering analysis was computed for the reduced Atlantic data sets using the 13 neutral loci (data not shown). No evidence supporting $>1$ population throughout the Atlantic nor hidden genetic structure was revealed.

Table 3. Lepeophtheirus salmonis. Pairwise fixation index $\left(F_{\mathrm{ST}}\right)$ values among lice collected from 11 locations throughout the Atlantic. Upper right matrix based on data from 13 neutral microsatellite loci; lower left matrix based on data from the single outlier locus LsalSTA3. * Significant difference at $\mathrm{p}=0.05,{ }^{* *}$ significant difference following Bonferroni correction (adjusted critical $\mathrm{p}=0.0009)$

\begin{tabular}{|lllllllllllll}
\hline Sample & N838 & N849 & F850 & F851 & I852 & I853 & N854 & S855 & S856 & C857 & C858 \\
\hline N838 & & -0.0008 & 0.0013 & -0.0002 & 0.0005 & 0.0023 & -0.0001 & 0.0018 & 0.0013 & $0.0024^{*}$ & $0.0028^{*}$ \\
N849 & 0.0027 & & 0.0010 & -0.0008 & 0.0002 & $0.0046^{*}$ & -0.0007 & 0.0018 & $0.0027^{*}$ & $0.0024^{*}$ & $0.0046^{*}$ \\
F850 & 0.0030 & $0.0043^{*}$ & & 0.0010 & 0.0018 & $0.0078^{* *}$ & $0.0028^{*}$ & $0.0047^{*}$ & $0.0055^{*}$ & $0.0033^{*}$ & $0.0042^{*}$ \\
F851 & 0.0016 & 0.0001 & 0.0006 & & 0.0012 & 0.0014 & 0.0002 & $0.0032^{*}$ & $0.0034^{*}$ & 0.0007 & $0.0026^{*}$ \\
I852 & $0.0136^{*}$ & $0.0237^{* *}$ & $0.0094^{*}$ & $0.0114^{*}$ & & $0.0041^{*}$ & 0.0016 & $0.0038^{*}$ & 0.0015 & 0.0022 & $0.0036^{*}$ \\
I853 & $0.0457^{* *}$ & $0.0704^{* *}$ & $0.0444^{* *}$ & $0.0526^{* *}$ & $0.0132^{*}$ & & $0.0038^{*}$ & 0.0005 & 0.0020 & $0.0029^{*}$ & 0.0015 \\
N854 & 0.0027 & 0.0014 & 0.0036 & -0.0007 & $0.0074^{*}$ & $0.0447^{* *}$ & & $0.0024^{*}$ & 0.0020 & $0.0032^{*}$ & $0.0043^{*}$ \\
S855 & $0.0141^{* *}$ & $0.0338^{* *}$ & $0.0135^{* *}$ & $0.0211^{* *}$ & 0.0043 & $0.0130^{*}$ & $0.0190^{* *}$ & & -0.0012 & 0.0015 & 0.0019 \\
S856 & $0.0542^{* *}$ & $0.0817^{* *}$ & $0.0502^{* *}$ & $0.0646^{* *}$ & $0.0213^{* *}$ & 0.0047 & $0.0563^{* *}$ & $0.0100^{*}$ & & $0.0033^{*}$ & 0.0022 \\
C857 & $0.0074^{*}$ & $0.0172^{* *}$ & $0.0140^{* *}$ & $0.0144^{* *}$ & $0.0291^{* *}$ & $0.0588^{* *}$ & $0.0158^{* *}$ & $0.0330^{* *}$ & $0.0790^{* *}$ & & -0.0002 \\
C858 & $0.0310^{* *}$ & $0.0421^{* *}$ & $0.0380^{* *}$ & $0.0395^{* *}$ & $0.0615^{* *}$ & $0.0893^{* *}$ & $0.0455^{* *}$ & $0.0603^{* *}$ & $0.1133^{* *}$ & $0.0065^{*}$ & \\
\hline
\end{tabular}


Table 4. Lepeophtheirus salmonis. Number of private alleles observed within countries when using (a) all 27 samples combined, and (b) 11 samples selected to represent the Atlantic distribution. Private $1=$ number of private alleles observed in a given country occurring as a single allele; Private $>1=$ number of private alleles observed in a given country occurring in $\geq 2$ individual lice

\begin{tabular}{|lrrrrrr|}
\hline & Norway & Faroe Islands & Shetland & Ireland & Canada & Total \\
\hline (a) & & & & & & \\
No. of lice & 1759 & 173 & 188 & 187 & 188 & 2495 \\
Private 1 & 21 & 3 & 1 & 3 & 3 & 31 \\
Private $>1$ & 29 & 0 & 1 & 0 & 0 & 30 \\
Total & 50 & 3 & 2 & 3 & 3 & 61 \\
(b) & & & & & & \\
No. of lice & 281 & 173 & 188 & 187 & 188 & 1017 \\
Private 1 & 13 & 7 & 4 & 6 & 6 & 36 \\
Private $>1$ & 2 & 1 & 2 & 2 & 0 & 7 \\
Total & 15 & 8 & 6 & 8 & 6 & 43 \\
\hline
\end{tabular}

tween pairs of samples within countries. The relationship between geographic and genetic distance was slightly stronger for the full Atlantic data set; however, this was clearly biased by the inclusion of the 19 samples from Norway that were both geographically and genetically close (data not shown).

\section{DISCUSSION}

To date, the present study represents the most extensive examination of Lepeophtheirus salmonis population genetic structure in the Atlantic. Although weak, statistically significant

A significant, albeit weak, relationship between geographic and genetic distance was observed within the reduced Atlantic data set when considering data from all 14 loci (Fig. 3). However, the outlier locus LsalSTA3 was clearly of major influence in this relationship. When it was excluded, no significant trend was detected with the remaining 13 loci pooled (Fig. 3). The observed relationship between geographic and genetic distance when LsalSTA3 was included in the analyses is consistent with the fact that none of the 33 pairwise $F_{\mathrm{ST}}$ values exceeding 0.01 when computed with all 14 loci in the complete data set were observed begenetic differentiation was detected, suggesting that L. salmonis displays subtle population genetic structure throughout this range. Additionally, a significant positive relationship between geographic and genetic distance was observed. The observed trend was modest, and caused almost entirely by the locus LsalSTA3, which was demonstrated to be a candidate for positive selection. However, this represents the first time that a significant relationship between geographic and genetic distance has been reported in this species, and may suggest some influence of isolation by distance. No evidence suggested the existence of strong local

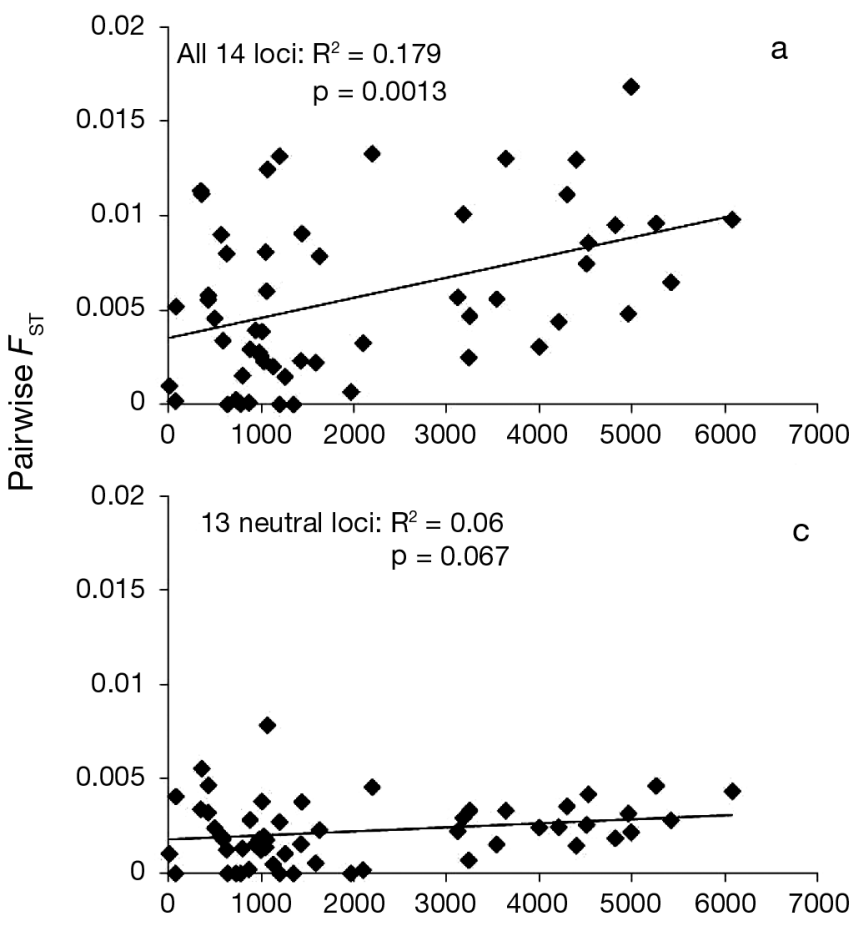

Pairwise distance between samples $(\mathrm{km})$

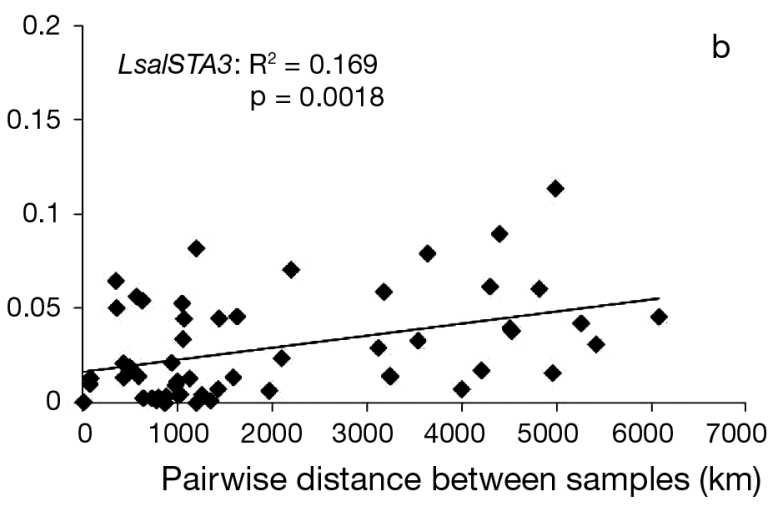

Fig. 3. Lepeophtheirus salmonis. Relationship between pairwise distance and fixation index $\left(F_{\mathrm{ST}}\right)$ among 1017 individuals originating from 11 samples throughout the Atlantic. Calculated with data from (a) all 14 microsatellite loci, (b) the outlier locus LsalSTA3 and (c) the 13 neutral loci excluding LsalSTA3 
genetic differentiation. The observed weak population genetic structure is consistent with the dispersal potential of this species, both at planktonic larvae stages and while attached to its salmonid hosts.

The population genetic structure of Lepeophtheirus salmonis has been subject to several investigations throughout the Atlantic. Tentatively, previous studies can be divided into those which have revealed weak (Tjensvoll et al. 2006) or no (Todd et al. 2004) population genetic structure, and those revealing significant levels of genetic differentiation, sometimes over very short distances (Dixon et al. 2004, Nolan \& Powell 2009). To varying degrees, previous studies may be subject to technical and sampling limitations, and results may be difficult to compare between marker classes. Looking past these potentially confounding effects, the magnitude of genetic differentiation observed among L. salmonis samples in the present study (reduced Atlantic data set: 13 loci: global $F_{\mathrm{ST}}=0.0022$; 14 loci: global $F_{\mathrm{ST}}=0.0057$; maximum 13 loci: pairwise $F_{\mathrm{ST}}=0.0078 ; 14$ loci: pairwise $F_{\mathrm{ST}}=0.0168$ ) appears intermediate to previous studies revealing no (Todd et al. 2004) or weak differentiation (Tjensvoll et al. 2006). Using data from the full sequence, Tjensvoll et al. (2006) reported maximum pairwise $F_{\mathrm{ST}}$ values of 0.013 for cytochrome $b(C y t b)$ and 0.01 for COI between a Canadian (Atlantic) and a Norwegian sample, in addition to a global $F_{\mathrm{ST}}$ value of 0.004 for both $C y t b$ and COI among samples collected in the Atlantic.

An earlier study conducted with 6 microsatellite DNA markers did not reveal any genetic structure throughout the Atlantic; overall $F_{\mathrm{ST}}$ was 0.0003 or -0.0004 , and pairwise $F_{\mathrm{ST}}$ values were 0 to 0.007 , none of which were statistically significant (Todd et al. 2004). They concluded that within the Atlantic Ocean, Lepeophtheirus salmonis is represented by a single population. In the present study, even when the locus LsalSTA3, which inflated $F_{\text {ST }}$ values, was excluded from the analyses, statistically significant overall genetic differentiation was observed among L. salmonis sampled from the Atlantic. Nevertheless, the largest pairwise $F_{\mathrm{ST}}$ value (based upon 13 loci) observed here was only slightly larger than largest pairwise $F_{\mathrm{ST}}$ value observed by Todd et al. (2004). We suggest that the more extensive analysis conducted within the present study (larger number of genetic markers and individuals) permitted the detection of weak population genetic structure (both pairwise and overall) where it was statistically non-significant in the study by Todd et al. (2004). For marine organisms potentially displaying high gene flow and large consensus and effective population sizes, robust sampling and larger numbers of loci may be required to delineate subtle population genetic structure. Furthermore, temporal sampling, to identify the stability of weak but nevertheless statisti- cally significant geographic genetic differentiation, is essential to validate the biological significance of such structuring (Knutsen et al. 2011). Together with analysis of greater numbers of markers to provide increased genome representation, temporal sampling will be required to fully elucidate the biological significance of the results presented here.

Several studies have reported highly significant genetic differentiation among samples of Lepeophtheirus salmonis collected within regions in countries (Dixon et al. 2004, Boulding et al. 2009, Nolan \& Powell 2009). However, none of those studies revealed any pattern to the genetic variation, nor detected a relationship between genetic and geographical distance. Looking closer, a study based on 4 microsatellite loci (Nolan \& Powell 2009) reported pairwise $F_{\mathrm{ST}}$ values as high as 0.184 among samples collected in Ireland, and a value of 0.123 for temporal samples on a single farm (July to September). A study based upon RAPD analysis (Dixon et al. 2004) reported a highest pairwise $F_{\mathrm{ST}}$ among samples from Scotland of 0.68 , and the majority $>0.2$. In a study of mtDNA in the Pacific (Boulding et al. 2009), which might not be directly comparable due to the large genetic differences between lice in the Pacific and Atlantic (Todd et al. 2004, Tjensvoll et al. 2006, Yazawa et al. 2008), a pairwise $F_{\mathrm{ST}}$ of 0.19 was reported between $L$. salmonis samples taken on wild and farmed salmon co-existing in the Broughton archipelago. Studies revealing highly significant genetic variation among groups of lice collected within a small region have suggested that their observations may reflect combinations of restricted gene flow, and/or post-settlement selection mediated through local environmental factors.

Groups of lice are potentially exposed to strong selective forces (e.g. salinity, temperature, medicated treatments) both pre- and post-settlement, and these forces may permit the development of genetic differentiation among groups of lice sampled within a small region (both between neighbouring farms and between wild and farmed fish). Ideally, such selection would be detected through the analysis of markers directly or tightly linked to the gene(s) under selection for the specific selective agent(s) in question. However, it is also theoretically possible to detect strong selection with neutral genetic markers if the effective population size is small enough to permit significant drift, and/or the selection is so intense that the groups of lice are exposed to a major genetic bottleneck. Nevertheless, given the fact that the effective population size of lice in most regions is likely to be high (due to large consensus population sizes), and in the light of the results from the 13 neutral microsatellite markers implemented in the present study (i.e. no evidence for significant genetic differentiation on a small geo- 
graphic scale, lack of genetic change before and after delousing on 5 farms, and weak genetic differentiation among 27 samples collected throughout the Atlantic), we find it unlikely that the results of previous studies revealing large genetic differences between groups of lice sampled in close proximity were largely caused by selection.

Salinity has been shown to be a highly significant factor modifying the population dynamics of Lepeophtheirus salmonis (Heuch et al. 2009), and medicated treatment has clear opportunities to influence survival. Furthermore, differences in host susceptibility (Glover et al. 2003, 2004, 2005, Glover \& Skaala 2006) may also influence groups of lice. Studies conducted on other marine copepods have revealed significant genetic variation among populations despite a high potential for dispersal (Bucklin et al. 2000, Oines \& Heuch 2007, Nuwer et al. 2008), and population-specific adaptations to salinity have been documented (Beyrend-Dur et al. 2009). Additionally, some copepod studies have revealed cryptic species as opposed to populations (Lee 2000, Chen \& Hare 2008), as evidenced by reproductive incompatibility (Lee 2000). In the present study, no evidence of cryptic population structure was observed.

Thus far, a larger number of population genetic studies of Lepeophtheirus salmonis have been published for lice collected in the Atlantic as opposed to the Pacific. Comparing results from these 2 oceans is of interest, but must be done with caution. This is in part due to the large genetic differences between lice collected from these 2 oceans (Todd et al. 2004, Tjensvoll et al. 2006, Yazawa et al. 2008), and in part due to the differences in the numbers, types and biology of hosts between the 2 oceans, both within and outside marine farms. Just as for studies conducted in the Atlantic, the 2 studies conducted within the Pacific display contrasting results. While analysis of COI (Boulding et al. 2009) revealed large genetic differences among samples of lice, including those collected on farmed and wild hosts in the same region, a recent and more extensive analysis of population genetic structure using 27 microsatellites and 87 SNPs from 25 loci failed to reveal temporal, spatial or host-specific (farm vs. wild) genetic variation within their sampling region (Messmer et al. in press). The latter study is more in accordance with the results of the present study, i.e. that the population genetic structure of $L$. salmonis both in the Atlantic and Pacific oceans is weak or non-existent.

In the present study, LsalSTA3 was identified as an outlier and a candidate for positive selection by the program LOSITAN (Antao et al. 2008). This locus has previously been used in 2 population genetic studies (Todd et al. 2004, Messmer et al. in press), neither of which reported it as an outlier. Clearly, it is not possi- ble to conclude why this locus was identified as a candidate for positive selection in the present study, and at the same time, displayed a statistically significant link (albeit relatively weak) between genetic and geographic distance. However, it is important to reiterate that that the analyses conducted on the Norway data set were almost identical with and without this locus included, whereas analyses conducted on the partial and full Atlantic data sets were heavily dependent upon its inclusion/exclusion. While the addition of markers under strong selection may provide biased results in respect of population delineation in an evolutionary context, they can still provide information of importance in ecological timescales (Nielsen et al. 2009). Clearly, identification of further loci under selection, especially to delousing agents, may offer us the ability to track contemporary dispersal of lice. This is a central issue for fisheries and aquaculture authorities concerned with the dispersal of lice displaying reduced sensitivity to delousing agents.

Acknowledgements. We acknowledge the assistance of farming companies for permitting access to sample lice on their fish, or for supplying samples of lice directly to the project. We thank G. Dahle, M. Q. Sánchez and 3 anonymous referees for helpful criticism of the manuscript. This project was funded by the Norwegian Ministry of Fisheries and the Institute of Marine Research.

\section{LITERATURE CITED}

Antao T, Lopes A, Lopes RJ, Beja-Pereira A, Luikart G (2008) LOSITAN: a workbench to detect molecular adaptation based upon a $F_{\mathrm{st}}$-outlier method. BMC Bioinformatics 9: 323

Berg OK, Berg M (1987) Migrations of sea trout, Salmo trutta L., from the Vardnes river in northern Norway. J Fish Biol 31:113-121

Beyrend-Dur D, Souissi S, Devreker D, Winkler G, Hwang JS (2009) Life cycle traits of two transatlantic populations of Eurytemora affinis (Copepoda: Calanoida): salinity effects. J Plankton Res 31:713-728

Bjørn PA, Finstad B (2002) Salmon lice, Lepeophtheirus salmonis (Krøyer), infestation in sympatric populations of Arctic char, Salvelinus alpinus (L.), and sea trout, Salmo trutta (L.), in areas near and distant from salmon farms. ICES J Mar Sci 59:131-139

Boulding EG, deWaard JR, Ang KP, Hebert PN (2009) Population genetic structure of the salmon louse, Lepeophtheirus salmonis (Krøyer) on wild and farmed salmonids around the Pacific coast of Canada. Aquacult Res 40:973-979

Bucklin A, Astthorsson OS, Gislason A, Allen LD, Smolenack SB, Wiebe PH (2000) Population genetic variation of Calanus finmarchicus in Icelandic waters: preliminary evidence of genetic differences between Atlantic and Arctic populations. ICES J Mar Sci 57:1592-1604

Burridge L, Weis JS, Cabello F, Pizarro J, Bostick K (2010) Chemical use in salmon aquaculture: a review of current practices and possible environmental effects. Aquaculture 306:7-23

Chen G, Hare MP (2008) Cryptic ecological diversification of a planktonic estuarine copepod, Acartia tonsa. Mol Ecol 
$17: 1451-1468$

Costello MJ (2006) Ecology of sea lice parasitic on farmed and wild fish. Trends Parasitol 22:475-483

Costello MJ (2009) The global economic cost of sea lice to the salmonid farming industry. J Fish Dis 32:115-118

> Dieringer D, Schlotterer C (2003) Microsatellite analyser (MSA): a platform independent analysis tool for large microsatellite data sets. Mol Ecol Notes 3:167-169

$>$ Dixon BA, Shinn AP, Sommerville C (2004) Genetic characterization of populations of the ectoparasitic caligid, Lepeophtheirus salmonis (Krøyer 1837) using randomly amplified polymorphic DNA. Aquacult Res 35:730-741

Fallang A, Ramsay JM, Sevatdal S, Burka JF, Jewess P, Hammell KL, Horsberg TE (2004) Evidence for occurrence of an organophosphate-resistant type of acetylcholinesterase in strains of sea lice (Lepeophtheirus salmonis Krøyer). Pest Manag Sci 60:1163-1170

Falush D, Stephens M, Pritchard JK (2003) Inference of population structure using multilocus genotype data: linked loci and correlated allele frequencies. Genetics 164: $1567-1587$

Glover KA, Skaala O (2006) Temporal stability of sea louse Lepeophtheirus salmonis Krøyer populations on Atlantic salmon Salmo salar L. of wild, farm and hybrid parentage. J Fish Biol 68:1795-1807

Glover KA, Skaala O, Nilsen F, Olsen R, Teale AJ, Taggart JB (2003) Differing susceptibility of anadromous brown trout (Salmo trutta L.) populations to salmon louse (Lepeophtheirus salmonis (Krøyer, 1837)) infection. ICES J Mar Sci 60:1139-1148

Glover KA, Hamre LA, Skaala O, Nilsen F (2004) A comparison of sea louse (Lepeophtheirus salmonis) infection levels in farmed and wild Atlantic salmon (Salmo salar L.) stocks. Aquaculture 232:41-52

Glover KA, Aasmundstad T, Nilsen F, Storset A, Skaala O (2005) Variation of Atlantic salmon families (Salmo salar L.) in susceptibility to the sea lice Lepeophtheirus salmonis and Caligus elongatus. Aquaculture 245:19-30

> Hansen LP, Jacobsen JA (2003) Origin and migration of wild and escaped farmed Atlantic salmon, Salmo salar L., in oceanic areas north of the Faroe Islands. ICES J Mar Sci 60:110-119

Heuch PA, Mo TA (2001) A model of salmon louse production in Norway: effects of increasing salmon production and public management measures. Dis Aquat Org 45:145-152

Heuch PA, Olsen RS, Malkenes R, Revie CW and others (2009) Temporal and spatial variations in lice numbers on salmon farms in the Hardanger fjord 2004-06. J Fish Dis 32:89-100

> Hoffman JI, Amos W (2005) Microsatellite genotyping errors: detection approaches, common sources and consequences for paternal exclusion. Mol Ecol 14:599-612

Holst JC, Nilsen F, Hodneland K, Nylund A (1993) Observations of the biology and parasites of postsmolt Atlantic salmon, Salmo salar, from the Norwegian sea. J Fish Biol 42:962-966

Jacobsen JA, Gaard E (1997) Open-ocean infestation by salmon lice (Lepeophtheirus salmonis): comparison of wild and escaped farmed Atlantic salmon (Salmo salar L.). ICES J Mar Sci 54:1113-1119

Johnson SC, Albright LJ (1991) Development, growth, and survival of Lepeophtheirus salmonis (Copepoda: Caligidae) under laboratory conditions. J Mar Biol Assoc UK 71:425-436

Johnson SC, Treasurer JW, Bravo S, Nagasawa K, Kabata Z (2004) A review of the impact of parasitic copepods on marine aquaculture. Zool Stud 43:229-243
Jones MW, Sommerville C, Wootten R (1992) Reduced sensitivity of the salmon louse, Lepeophtheirus salmonis, to the organophosphase dichlorvos. J Fish Dis 15:197-202

Jonsson B (1985) Life-history patterns of fresh-water resident and sea-run migrant brown trout in Norway. Trans Am Fish Soc 114:182-194

> Knutsen H, Olsen EM, Jorde PE, Espeland SH, André C, Stenseth NC (2011) Are low but statistically significant levels of genetic differentiation in marine fishes 'biologically meaningful'? A case study of coastal Atlantic cod. Mol Ecol 20:768-783

Krkošek M, Ford JS, Morton A, Lele S, Myers RA, Lewis MA (2007) Declining wild salmon populations in relation to parasites from farm salmon. Science 318:1772-1775

Lee CE (2000) Global phylogeography of a cryptic copepod species complex and reproductive isolation between genetically proximate 'populations'. Evolution 54: 2014-2027

Lees F, Baillie M, Gettinby G, Revie CW (2008) The efficacy of emamectin benzoate against infestations of Lepeophtheirus salmonis on farmed Atlantic salmon (Salmo salar L) in Scotland, 2002-2006. PLoS ONE 3(2):e1549

Messmer AM, Rondeau EB, Jantzen SG, Lubieniecki KP, Davidson WS, Koop BF (in press) Assessment of population structure in Pacific Lepeophtheirus salmonis (Krøyer) using single nucleotide polymorphism and microsatellite genetic markers. Aquaculture doi:10.1016/j.aquaculture. 2010.9.003

> Morton A, Routledge R, Peet C, Ladwig A (2004) Sea lice (Lepeophtheirus salmonis) infection rates on juvenile pink (Oncorhynchus gorbuscha) and chum (Oncorhynchus keta) salmon in the nearshore marine environment of British Columbia, Canada. Can J Fish Aquat Sci 61: 147-157

Nielsen EE, Wright PJ, Hemmer-Hansen J, Poulsen NA, Gibb IM, Meldrup D (2009) Microgeographical population structure of cod Gadus morhua in the North Sea and west of Scotland: the role of sampling loci and individuals. Mar Ecol Prog Ser 376:213-225

> Nolan DV, Powell R (2009) Geographic and temporal genetic structure in Lepeophtheirus salmonis from four salmon farms along the northwest and west coasts of Ireland: results from a microsatellite analysis. Hydrobiologia 617 : $55-63$

Nolan DV, Martin SAM, Kelly Y, Glennon K and others (2000) Development of microsatellite PCR typing methodology for the sea louse, Lepeophtheirus salmonis (Krøyer). Aquacult Res 31:815-822

> Nuwer M, Frost B, Armbrust EV (2008) Population structure of the planktonic copepod Calanus pacificus in the North Pacific Ocean. Mar Biol 156:107-115

> Oines O, Heuch PA (2007) Caligus elongatus Nordmann genotypes on wild and farmed fish. J Fish Dis 30:81-91

> Pike AW, Wadsworth SL (2000) Sealice on salmonids: their biology and control. Adv Parasitol 44:233-337

> Pompanon F, Bonin A, Bellemain E, Taberlet P (2005) Genotyping errors: causes, consequences and solutions. Nat Rev Genet 6:847-859

Pritchard JK, Stephens M, Donnelly P (2000) Inference of population structure using multilocus genotype data. Genetics 155:945-959

Raymond M, Rousset F (1995) GENEPOP (version-1.2) — population-genetics software for exact tests and ecumenicism. J Hered 86:248-249

Sevatdal S, Horsberg TE (2003) Determination of reduced sensitivity in sea lice (Lepeophtheirus salmonis Krøyer) against the pyrethroid deltamethrin using bioassays and probit modelling. Aquaculture 218:21-31

Tjensvoll K, Glover KA, Nylund A (2006) Sequence variation 
in four mitochondrial genes of the salmon louse Lepeophtheirus salmonis. Dis Aquat Org 68:251-259

Todd CD, Walker AM, Wolff K, Northcott SJ and others (1997) Genetic differentiation of populations of the copepod sea louse Lepeophtheirus salmonis (Krøyer) ectoparasitic on wild and farmed salmonids around the coasts of Scotland: evidence from RAPD markers. J Exp Mar Biol Ecol 210: 251-274

Todd CD, Walker AM, Ritchie MG, Graves JA, Walker AF (2004) Population genetic differentiation of sea lice (Lepeophtheirus salmonis) parasitic on Atlantic and Pacific salmonids: analyses of microsatellite DNA variation among wild and farmed hosts. Can J Fish Aquat Sci 61: $1176-1190$

Treasurer JW, Wadsworth S, Grant A (2000) Resistance of sea lice, Lepeophtheirus salmonis (Krøyer), to hydrogen peroxide on farmed Atlantic salmon, Salmo salar L. Aquacult

Editorial responsibility: Hans Heinrich Janssen, Oldendorf/Luhe, Germany
Res 31:855-860

Tully O, McFadden Y (2000) Variation in sensitivity of sea lice [Lepeophtheirus salmonis (Krøyer)] to dichlorvos on Irish salmon farms in 1991-92. Aquacult Res 31:849-854

Tully O, Gargan P, Poole WR, Whelan KF (1999) Spatial and temporal variation in the infestation of sea trout (Salmo trutta L.) by the caligid copepod Lepeophtheirus salmonis (Krøyer) in relation to sources of infection in Ireland. Parasitology 119:41-51

Van Oosterhout C, Hutchinson WF, Wills DPM, Shipley P (2004) MICRO-CHECKER: software for identifying and correcting genotyping errors in microsatellite data. Mol Ecol Notes 4:535-538

Yazawa R, Yasuike M, Leong J, von Schalburg KR and others (2008) EST and mitochondrial DNA sequences support a distinct Pacific form of salmon louse, Lepeophtheirus salmonis. Mar Biotechnol 10:741-749

Submitted: June 14, 2010; Accepted: January 19, 2011 Proofs received from author(s): March 25, 2011 